\title{
LEARNING STRATEGIES USED BY THE STUDENTS OF ENGLISH DEPARTMENT OF TARBIYAH FACULTY AT STAIN PALOPO
}

\author{
Nurhidayah J \\ Fakultas Kesehatan Masyarakat, Universitas Indonesia Timur \\ yaya_misscozy@rocketmail.com
}

\begin{abstract}
The objectives of this research were: (1) to find out of the six learning strategies, which learning strategies applied by high achievers of English Department of Tarbiyah Faculty at STAIN Palopo; (2) to find out the most frequently strategies used by the students of English Department of Tarbiyah Faculty at STAIN Palopo; (3) to find out differences between high achievers and low achievers in their learning strategies. In analyzing the data, the researcher applied quantitative method. The subject was the sixth semester students of English Department STAIN Palopo. This research used questionaire SILL as instrument. The result of the research showed that (1) the strategies applied by high achievers in memory strategy was "review English lessons". In the cognitive strategies applied "trying to talk like native speakers". In the compensation strategies "using synonym in case they couldn't think of a word". The high achievers always or almost always used all metacognitive strategy. They applied "try to find how to be a better learner". In affective strategy "talk to someone else about how I feel". In social strategy applied "ask others to speak slowly or repeat" if they do not understand something in second language. (2) Metacognitive strategies is the most frequently strategy used by sixth semester students of English Department of STAIN Palopo with mean 3.3755. (3) There is a significant different in using language learning strategies between high achievers and low achievers. The highest frequently used by high achievers is metacognitive strategies and the lowest frequently used is memory strategies. Meanwhile, the highest frequently used by low achievers is affective strategies and the lowest frequently used is memory strategies.
\end{abstract}

Keywords: Learning Strategies, quantitative method, metacognitive strategies, memory strategies, cognitive strategies

\section{INTRODUCTION}

During the learning process, one might find that some people can learn every subject or several subjects very quickly and well. On the other hand, some people have problems in learning. Therefore, many researches try to find how learners go about learning something, what makes learners successful at learning something, and why some people are more effective at learning than others. 
Williams \& Burden (1997) point out, that can only be answered by investigating learning strategies.

Learning strategies are the conscious thoughts and actions that learners take in order to achieve a learning goal. Strategic learners have metacognitive knowledge about their own thinking and learning approaches, a good understanding of what a task entails, and the ability to orchestrate the strategies that best meet both the task demands and their own learning strengths (Chamot, 2004).

Language learning strategies are good indicators of how learners approach tasks or problems encountered during the process of language learning. In other words, language learning strategies, while nonobservable or unconsciously used in some cases, give language teachers valuable clues about how their students assess the situation, plan, select appropriate skills so as to understand, learn, or remember new input presented in the language classroom.

Research on language learning strategies began with the strategies of the “good language learner" by Rubin (1975) and Stern (1975). From these initial research efforts, numerous researchers have attempted to emphasize the importance of language learning strategy use by successful language learners (e.g., Abraham \& Vann, 1987, 1990; Chamot \& Kupper, 1989; Naiman, Frolich, Stern, and Todesco, 1978; O’Malley \& Chamot, 1990; Oxford et al., 1989,1993, 1995; Politzer \& McGroarty, 1985; Ramsey, 1980; Reiss, 1983). The researchers believe that language learning strategy plays a significant role in L2/FL learning, due to the fact that language learning strategies that can help learners to facilitate the acquisition, storage, retrieval or use of information and increase selfconfidence.

Strategies that applied will be different from learners to learners. The choice of the strategies is also determined by the personality of the learners. Freeman (1991) stated that the personality has a lot to do with how fast and easily the learners learn a foreign language. If the learners are more outgoing and not afraid to take a risk, the learners are the type of person who is not afraid to take a risk, the learners are the type of person who is not afraid to practice our new 
language skills. In addition, being aware of how the learners learn is an important factor. If the learners know how to take charge of their learning, the learners will learn faster.

They do not only aid language learning, but also the learning of other subjects such as maths, chemistry, etc. In other words, when learners start to learn something, they have the ability to respond to the particular learning situation and to manage their learning in an appropriate way. Thus, learning strategy is like footballers who use tactics in order to win a game, when they are in the stadium. Learners use learning strategies in order to learn something more successfully.

Based on finding of the research and theory about learning strategies above, can conclude that learning strategies have been applied by many students especially students of university. It is possible also occur on students of English Department of STAIN Palopo. Varieties of learning strategies automatically are used by them.

From fact showed above the researcher was interest in conducting a research entitled "Learning Strategies Used by the Students of English Department of STAIN Palopo".

In relation to the issues put forward in the background and refers to the objectives that the researcher wanted to get, here the researcher formulated the following problem statements:

1. Six learning strategies, which learning strategies applied by high achievers in sixth semester of English Department of Tarbiyah Faculty at STAIN Palopo?

2. What are the most frequently used learning strategies by students in sixth semester of English Department of Tarbiyah Faculty at STAIN Palopo ?

3. Is there any differences between the high achievers and low achievers in their learning strategies?

The following points are considered as the objectives of the research:

1. To find out of the six learning strategies, which learning strategies applied by high achievers in sixth semester of English Department of Tarbiyah Faculty at STAIN Palopo. 
2. To find out the most frequently used learning strategies by students in sixth semester of English Department of Tarbiyah Faculty at STAIN Palopo.

3. To find out the differences of learning strategies between high achievers and low achievers.

\section{LITERATURES}

Learning strategies have received much attention since the late 1980s (Oxford, 2008) and the investigation of language learning strategies has advanced our understanding of the processes learners use to develop their skills in a second or foreign language. Reiss (1985) reported that during the past decade, the emphasis on foreign language research has shifted from the teacher to the learner, and educational research had identified a number of factors that account for some of the differences in how students learn. There are some studies have been conduct in relation to teaching and learning strategies of English as foreign language.

The studies are presented below Chang, Ching-Yi et al. (2007) conducted research entitled "A Study of Language Learning Strategies Used by College EFL Learners in Taiwan". The study was designed to investigate the influence of gender and major on college EFL learning strategy use in Taiwan. A total of 1758 Taiwanese college EFL learners took part in this research study. The participants completed the two sets of self-reported questionnaires, including Background Characteristics and Strategy Inventory for Language Learning (SILL) (Oxford, 1989). The collected data were computed and analyzed via descriptive statistics, $t$ test, and one-way ANOVA.

The findings of the study were generalized as follows: (1) There was not a great difference among the frequency of each strategy that Taiwanese college EFL learners report using, all in medium-use level. (2) Statistically significant differences were found in the use of cognitive strategies, metacognitive strategies, social strategies and overall strategies with regard to gender. (3) Statistically 
significant differences were found in the use of six subcategories of language learning strategies and overall strategies with regard to major.

Anna (2004) conducted research entitled "Issues in Language Learning Strategy Research and Teaching". The research discusses current issues in language learning strategy research that affect teachers and learners of foreign languages. The issues include: identification procedures of learning strategies, terminology and classification of strategies, the effects of learner characteristics on strategy use, the effects of culture and context on strategy use, explicit and integrated strategy instruction, language of instruction, transfer of strategies to new tasks, and models for language learning strategy instruction.

These eight issues are explored through a discussion of existing research that illumines the issues. The researcher have asked language learners to describe their learning processes and strategies through retrospective interviews, stimulated recall interviews, questionnaires, written diaries and journals, and think-aloud protocols concurrent with a learning task. Each of these methods has limitations, but each provides important insights into unobservable mental learning strategies.

Chien (2010) conducted research entitled "An Overview Of Language Learning Strategies". The research focuses on previously published literature on language learning strategies. The variable research affecting language learning strategies will be illustrated; theoretical background and current issues will be examined as well. The research aims to talk about the development of language learning strategy since the 1970s. It provide information about of the use of language learning strategies, which will enhance English learning for non-native learners. Further, the better understanding of language learning strategies for English teachers can help students to learn more successfully and develop their learning autonomy. The research also serve as a research reference in the field of language learning strategies, particularly the relationship between a different language learning cultural background and the use of strategy as well as leading us to the current status of learning strategies and learning strategies instruction.

Jirapa (2008) conducted research entitled "The Implications Of Learner Strategies For Second Or Foreign Language Teaching”. The research critically 
reviews previous research on learner strategies and the implications of learner strategies for language teaching will be addressed. It aims to give some ideas to language teachers or administrators of how to: (1) explicitly involve learner strategies in a language curriculum, (2) provide language learners with a menu of the strategies that they can choose and adapt to different language learning tasks, and (3) create habits of good language learners.

Haryanto (1999) conducted a research under the title "Motivation and Learning Strategies of a good Indonesian EFL Learner". He investigated deeply a good Indonesian EFL learner named Indra. Focusing in two question : What learning strategies are performed by him and how does his motivation operate to achieve success of EFL in Indonesian context. By applying grounded theory approach, he concluded that there are two main factors determining the success of Indra in learning English, namely motivation and learning strategies. Beside that, there are also other factors that peripherally give contribution to his success including attitude, intelligence, parents' role, material design, school environment, and school policy.

Arifin (2000) also conducted the research under the tittle "Language Learning Strategy in Second Language Acquisition by Adult Learners of English in the Indonesian Context", he found out that adult learners learn English neither for curriculum requirement nor for any kind of examination ratings. They rather learn English for the purpose of equipping themselves with other qualities required to cope with potential job problems arising from or associated with inability of the English language. He also found that English learning behavior of Indonesian adults may be characterized to fall into transitional phase from cognitive orientation to social and metacognitive learning pattern.

\section{METHOD}

In this research, the researcher applied quantitative method research design. According to Onweugbuzie and Leech (2006), the term QUAN (an abbreviation of quantitative approach) refer to research design involving data quantification. Thus, the data are numerical and analyzed using statistical 
formulas, either the simple or the complicated. The simplest and the most common analysis techniques include the formula used to compute measures of central tendency (e.g., mean, median, mode), measures of position/location (e.g., percentile rank, z-score) and measures distributional shape (i.e., skewness, kurtosis). The other rather complicated statistics formulas include correlation coefficient, t-test, one-way analyses of variance (ANOVA), and simple linear regression.

Research design under QUAN researches involving the statistic analysis are survey, correlation studies, experiments, and quasi-experiments. Gay et al (2006) also include descriptive research and causal-comparative research under QUAN research methods.

The quantitative data in this research involving analysis frequency, descriptive statistics, t-test and ANOVA procedure. The quantitative data was collected through questionnaire which aim to identify students' language learning strategies. The SILL questionnaire (Strategies Inventory of Language Learning) developed by Rebecca Oxford was used in this research. The questionnaire were distributed to the students. The subjects of this research were the sixth semester students of English Department Tarbiyah Faculty at STAIN Palopo. There were three groups, called Tadris Inggris A, B and C. The total of research subjects was 93 students. 15 students identify as high achievers and 14 students as low achievers. The researcher selected sixth semester students because they are assumed to be relatively more capable of selecting and using appropriate learning strategies compared with fourth semester students and second semester students.

The researcher used Strategy Inventory for Language Learning (SILL) version 7.0 as instrument to collect the data in this research. Questionnaire was used to get quantitative data about learning strategies of the students. One of the most widely used measures has been the Strategy Inventory for Language Learning (SILL). (Dörnyei 2005, White, Schramm and Chamot 2007). It is a structured questionnaire, aiming to assess how often learners employ specific language learning strategies. 
It equips teachers with the strategy profile of their students and uncovers to learners the kinds of strategies they resort to when learning English as a second or foreign language (Oxford 1990).

The data are processed by Statistical Package for Social Sciences (SPSS) 20. Descriptive statistic was used to investigate the frequently used learning strategies by students in the sixth semester students of English Departement of Tarbiyah Faculty at STAIN Palopo. The 0,05 level of statistical significance was set all statistical test in this research.

\section{FINDINGS}

As what stated in chapter 1 that this research aims to find learning strategies applied by high achievers, to find the frequently used learning strategies and the differences between high achievers and low achievers in using their learning strategies. In this section, the research findings as what have been presented in the previous chapter. Quantitative data was obtained from questionnaires (LLSs by Oxford).

\section{Learning Strategies applied by high achievers}

Based on the finding, it shows the frequency score and the high mean score in memory strategies that applied by high achievers. The high frequency total is 36. Based on score rate in questionaire, score 4 is "usually". The high mean score memory strategies was statement in SILL that is "review English lessons". It means that high achivers usually review their English lessons. The frequency score and the high mean score in cognitive strategies that applied by high achievers. The high frequency total is 69. Based on score rate in questionaire, score 4 is "usually". The high mean score in cognitive strategies that applied by high achievers was the second statement, in questionaire SILL number 11 that is "try to talk like native speakers". It means that high achivers usually try to talk like native speakers.

The frequency score and the high mean score in compensation strategies that applied by high achievers. The high frequency total is 26 , based on score rate in questionaire, score 3 is "somewhat true". The high mean score in 
compensation strategies that applied by high achievers was the sixth statement, in SILL number 29 that is "if I cant think of a word I use a synonym". It means that high achievers somewhat use a synonym or phrase that means the same thing if they cant think of a second language word.

The frequency score and the high mean score in metacognitive strategies that applied by high achievers. The high frequency total is 54 , based on score rate in questionaire, score 4 is "usually". The high mean score in metacognitive strategies that applied by high achievers among the metacognitive strategies was the fourth statement, in SILL number 33 that is "try to find how to be a better learner". It means that high achivers usually try to find how to be a better learner of second language.

The frequency score and the high mean score in affective strategies that applied by high achievers. The high frequency total is 26 based on score rate in questionaire, score 3 is "somewhat true". The high mean score in affective strategies that applied by high achievers was the sixth statement, in SILL number 44 that is "talk to someone else about how I feel". It means that high achievers somewhat talk to someone else about how they feel when they are learning English.

The frequency score and the high mean score in affective strategies that applied by high achievers. The high frequency total is 30 , based on score rate in questionaire, score 4 is "usually". The high mean score in social strategies that applied by high achievers was the first statement, in SILL number 45 that is "ask others to speak slowly or repeat". It means that high achievers usually ask other person to slowly or repeat again if they do not understand something in second language. These results seem to show that sixth semester students of English Department of Tarbiyah faculty at STAIN Palopo have high awareness and willingness in learning English.

\section{The Most Frequenlty Used Language Learning Strategies}

The sixth semester students used metacognitive strategies. The most frequently used strategy was Metacognitive strategies $(M=3.3755)$ and followed 
by Affective strategies $(M=3.2471)$, Cognitive strategies $(M=3.2315)$, Social strategies $(M=3.1552)$, Compensation strategies $(M=3.1494)$ and Memory strategies $(M=2.9885)$.

This result is consistent with several related studies. For examples, Carol (2010) who found the strategies used by two successful learners, Nina and Kira, and considers the effect of other learner variables (motivation, nationality, age, gender, personality) on successful language learning. The research concludes that succesful learners was used metacognitive strategies.

The second is O'Malley (1985). He found that higher level students reported greater use of metacognitive strategies (that is strategies used by students to manage their own learning), leading the researchers to conclude that the more successful students are probably able to exercise greater metacognitive control over their learning. The third is Sarig finding (1987). She found that a fifth of all strategy use reported by the students were combinations of cognitive strategies, metacognitive strategies, or both, cognitive and metacognitive strategies.

The fourth are Nambiar (1996) and Mah (1999). They found that Malaysian undergraduates used strategies in combination, especially from the cognitive and metacognitive strategy groups. This is an important finding because it helps us understand why some learners are more successful at completing a language task compared to others. The fifth are Rahimi, Ruazi and Saif's (2004). They found that the Persian EFL learners' highest use of metacognitive strategies and lowest use of memory strategies.

The sixth is Arifin (2000). He found that English learning behavior of Indonesian adults may be characterized to fall into transitional phase from cognitive orientation to social and metacognitive learning pattern. The seventh are Chang, Ci-Yi et al. (2007). They found that statistically significant differences were found in the use of cognitive strategies, metacognitive strategies, social strategies and overall strategies with regard to gender. They also found statistically significant differences were found in the use of six subcategories of language learning strategies and overall strategies with regard to major. The study was designed to investigate the influence of gender and major on college EFL 
learning strategy use in Taiwan. Based on several related studies above it can be concluded that the higher level students most frequent use metacognitive strategies which are "behaviors used for centering, arranging, planning, and evaluating one's learning”.

\section{The Differences of Using Language Learning Strategies between High Achievers and Low Achievers}

This research also examined the differences between learning strategies and academic performance of sixth semester students of English Department STAIN Palopo. The subjects of this research were high achievers and low achievers based on their grade point average.This research found the frequently used by high achievers was metacognitive strategy, followed with cognitive strategy, social strategy, affective strategy, memory strategy and compensation strategy.

Meanwhile, the high strategy categories used by low achievers was affective strategy, followed with metacognitive strategy, compensation strategy, cognitive strategy, social strategy and memory strategy.

The result of this research indicated that there is a significant different in using language learning strategies between high achievers and low achievers. The more the learning strategies used, the higher the student performance was. This result is consistent with the results of Griffiths (2003), who maintains that highly frequently use the strategies relating to interaction with others, to vocabulary, to reading, to the tolerance of ambiguity, to language systems, to the management of feelings, to the management of learning and to the utilisation of available resources.

\section{CONCLUSION}

Based on the findings and discussion in the previous chapter, the research concludes the result of this research as follows:

1. From the six learning strategies, the most frequency used learning strategies by high achievers is metacognitive strategy, followed with cognitive strategy, social strategy, affective strategy, memory strategy and 
compensation strategy. In memory strategy high achievers applied "review English lessons". In the cognitive strategies high achievers applied "trying to talk like native speakers ${ }^{e}$. In the compensation strategies high achievers applied "using synonym in case they couldn't think of a word". The high achievers always or almost always used all metacognitive strategy. They applied "try to find how to be a better learner" in metacognitive strategy. In affective strategy high achivers applied "talk to someone else about how I feel". In social strategy the high achievers applied "ask others to speak slowly or repeat" if they do not understand something in second language.

2. Metacognitive strategies is the most frequently strategy used by sixth semester students of English Department of STAIN Palopo $(M=3.3755)$ and followed by Affective strategies $(M=3.2471)$, Cognitive strategies $(M$ $=3.2315)$, Social strategies $(M=3.1552)$, Compensation strategies $(M$ $=3.1494)$ and Memory strategies $(M=2.9885)$.

3. There is a significant difference in used language learning strategies between high achievers and low achievers. The most frequently used by high achievers is Metacognitive strategies and the lowest frequently used is Memory strategies. Meanwhile, the most frequently strategy used by low achievers is Affective strategies and the lowest frequently used is Memory strategies.

\section{SUGGESTION}

Based on the conclusion above, the researcher provides some suggestions and recomendation as follow :

1. Applying metacognitive strategies help the learners, especially to low achiever to get improvement in their English. Try to find many ways to use English, use mistakes to help do better, try to find how to be a better learner, look for opportunities to read English and think about progress in English are more of the ways to improve the learners' English ability.

2. Students should be made awareness that a wider repertoire of LLSs and higher frequency of their use are both critical in learning language 
effectively. Some other factors affecting the choice of language learning strategies like motivation, attitude, learning style, economic situation, social background should be involved in further research.

\section{BIBLIOGRAPHY}

Anna Uhl Chamot. 2004. Issues in Language Learning Strategy Research and Teaching. Electronic Journal of Foreign Language Teaching. Vol. 1, No. 1, (pp. 14-26.) Centre for Language Studies. National University of Singapore. Atmowardoyo, Haryanto. 2000. Research Methods For Language And Literature Studies. Makassar. Badan penerbit UNM.

Chang, Ching-Yi \& Liu, Shu-Chen \& Lee, Yi-Nan. 2007. A Study of Language Learning Strategies Used by College EFL Learners in Taiwan.

Chang, S. J. and S. C. Huang. 1999. Language Learning Motivation and Language Strategies of Taiwanese EFL Students. Washington, DC: Department of Education. [ERIC: Document Reproduction Service No. ED371589].

Chen, Yueh-miao. 2005. The Learning Strategies of Taiwanese University Students: English Majors Versus Non-English Majors and Males Versus Females. Indonesian Journal of English Language Teaching, Vol. 1/no.2.

Gay, et al. 2006. Educational Research. New Jersey: Pearson Prentice Hall.

Ghadesi, M. 1998. Language Learning Strategies of Some University Students in Hong Kong. Paper presented at the $9^{\text {th }}$ English in Southeast Asia Conference. Brunei.

Griffiths. 2010. Strategies of Successful Language Learners. JELS, Vol. 1, No. 3, Spring (pp.1-18).

Green, J. M., and Oxford, R. 1995. A Closer Look at Learning Strategies, L2 Proficiency, and Gender. TESOL Quarterly, 29(2), (pp. 261-297).

Larsen-Freeman, Diane, and Long, Michael H. 1991. An Introduction to Second Language Acquisition Research. New York: Longman Inc.

Mamuna. 2003. Language Learning Strategies Employed by L2 Learners. Department of English, Islamia University Bahawalpur. Journal of Research (Faculty of Languages \& Islamic Studies) Vol.4 
O’Malley, J. M., Chamot, A. U., Stewner-Manzanares, G., Russo, R., \& L. Küpper. 1985. Learning Strategy Applications with students of English as a Second Language. TESOL Quarterly, 19 (3), (pp. 557-584).

O’Malley, J. M. and Chamot, A. U. 1990. Learning Strategies in Second Language Acquisition. Cambridge: Cambridge University Press.

Oxford, R.L. 1990a. Language Learning Strategies and Beyond: A Look at Strategies in the Context of Styles. In S.S. Magnan (Ed.), Shifting the Instructional Focus to the Learner (pp. 35-55). Middlebury, VT: Northeast Conference on the Teaching of Foreign Languages.

Oxford, R. L., and Crookall, D. 1989. Research on Language Learning Strategies: Method, Findings, and Instructional Issues. Modern Language Journal, 73, (pp. 404-419).

Oxford, R. and M. Nyikos. 1989. Variables Affecting Choice of Language Learning Strategies by University Students. Modern Language Journal, 73, (pp. 291-300).

Peacock, M. and B. Ho. 2003. Students Language Learning Strategies Across Eight Disciplines. International Journal of Applied Linguistic, 13, (pp. 179200).

Rahimi, Riazi and Saif. 2004. An Investigation into the Factors Affecting the Use of Language Learning Strategies By Persian EFL Learners. RCLA. CJAL Journal, 11, (pp.31-60).

Rubin, J. 1987. Learner Strategies: Theoretical Assumptions, Research History and Typology. In A. Wenden and J. Rubin (Eds.), Learner Strategies and Language Learning. (pp. 15-29). Englewood Cliffs, New Jersey: Prentice Hall.

Rubin, J. W. 1975. What the 'Good Language Learner' Can Teach Us. TESOL Quartely, 9, (pp.41-51).

Rubin, and Wenden, A. 1987. Learner Strategies in Language Learning. Englewood Cliffs: Prentice Hall.

Rubin, J., and Thompson, I. 1982. How to be a More Successful Language Learner. Boston: Heinle \& Heinle. 